\title{
Formes de mystique dans le Nord préchrétien
}

\author{
ÉTUDE PSYCHOLOGIQUE
}

Par ÅE V. STRÖM, Lund

\section{Introduction}

Une conférence sur ce sujet n'aurait pas pu être faite il y a quelques années. La mystique dans le Nord ancien n'était pas reconnue. Nous pouvons le constater et dans les écrits sur la mystique en général, et dans ceux sur la religion des pays du Nord. Dans son livre sur la mystique païenne et chrétienne le savant dano-suédois Edv. Lehmann expose la mystique dans à peu près toutes les formes de la religion - sauf celle des Germains ${ }^{1}$. La mystique allemande commence, pour lui, avec Hildegard de Bingen ${ }^{2}$. Chez le nordiste danois Axel Olrik se trouve, certes, le terme "mystische Religiosität » dans l'index de son livre Nordisches Geistesleben, mais - les pages mentionnées se rapportent à l'époque chrétienne des chansons folkloriques's! Même l'Encyclopédie scandinave sur le Moyen Age, en voie de publication, ne donne,

${ }^{1}$ Edv. Lehmann, Mystik $i$ Hedenskab og Kristendom, Copenhague 1904.

${ }^{2}$ Lehmann, pp. I59-162. - Les Germains sont non plus décrits dans H. Delacroix, Etudes d'historie et de psychologie du mysticisme, Paris I908, James H. Leuba, The Psychology of religious Mysticism, (1925) éd. rev. Londres 1929, Vilh. Grønbech, Mystikere i Europa og Indien, I-IV, Copenhague 1925-34, Georg Mehlis, Die Mystik in der Fülle ihrer Erscheinungsformen in allen Zeiten und Kulturen (1), Munich 1926, Tor Andrae, Mystikens psykologi, Upsal 1926, $2^{\mathrm{e}}$ éd. 1968, R. F. Merkel, Die Mystik im Kulturleben der Völker, Hambourg 1940, Sidney Spencer, Mysticism in World Religion, Londres I 966 (toutes les religions), ou les articles "Mysticism 》, Encyklopedia of Religion and Ethics, 9, Edinburgh r917, pp. 83-Ir7, et "Mystik》, Die Religion in Geschichte und Gegenwart, IV, Tübingen 1960, col. 1239-124I.

${ }^{3}$ Axel Olrik, Nordisches Geistesleben, Heidelberg I 908, pp. I 54-1 58. Le mot mystique manque dans l'index de, entre autre, les ouvres suivantes: Vilh. Grønbech, The Culture of the Teutons, I-3, Londres-Copenhague I93 I, Jan de Vries, Altgermanische Religionsgeschichte, $2^{\mathrm{e}}$ éd. I-2, Berlin 1956-1957, Folke Ström, Nordisk hedendom, Lund I961, $2^{\circ}$ ed. 1967, E. O. G. Turville-Petre, Myth and Religion of the North, New York 1964 . 
dans l'article "Mystique ", que de la matière chrétienne ${ }^{1}$. Une seule œuvre, à notre connaissance, du temps ancien, contient un point de vue y appartenant, à savoir le thèse de M. Philippe de Félice sur quelques formes inférieures de la mystique, qui comprend un chapître sur "L'ivresse sacrée chez les Germains »2.

Et pourtant il existait plusieurs formes de mystique parmi les Germains anciens et dans le Nord préchrétien. Naturellement ceci est partiellement dû à la façon dont on détermine la notion de mystique. Chez les Septentrionaux préchrétiens nous ne trouvons pas une scala mystica, pareille à celle de Sainte Thérèse d'Avila, ou à celle qui est représentée dans le rāja-yoga de Patañjaliª, ni de vision de dieu (avec un petit nombre d'exeptions) ou d'incorporation avec la divinité. Mais si nous suivons la classification en mystique douce et mystique extrème de M. James B. Pratt ${ }^{4}$, cette dernière forme se trouve absolument chez les anciens Germains, comme une manière d'atteindre une réalité surnaturelle par d'autres voies de connaissance et d'expérience que les ordinaires $^{5}$. Sous quelles formes se présente cette mystique dans le Nord?

D'abord nous mentionnons une forme qui a apparemment manqué : la mystique cosmologique et astrologique qu'on rencontre ailleurs. Le germaniste allemand Heinrich Hempel et le slaviste suédois Sigurd Agrell pensaient, vers I930, que les I 2 dieux et les demeures célestes dans les Grímnismál 4-I7, représentaient les I2 signes du zodiaqué ${ }^{6}$. Mais cela est sans doute une erreur. Et quand Snorri dans le Formáli de son Edda dit que « quelqu'un devait être le supérieur des corps célestes, quelqu'un qui dirigeait leur cours

${ }^{1}$ Lars Rooth, l'art. "Mystik", Kulturhistoriskt lexikon för nordisk medeltid, 12, Malmoe 1967, col. I03-105.

${ }^{2} \mathrm{Ph}$. de Félice, Essai sur quelques formes inférieurs de la mystique, Paris 1936, pp. 336-356. - Cp. Mircea Eliade, Le chamanisme, Paris I95 I, chap. "Techniques d'extase chez les anciens Germains ", pp. 342-348.

${ }^{3}$ Voir la comparaison entre les deux dans H. Ringgren-Åke V. Ström, Les religions du monde, Paris 1960 , pp. 2 i 6 et suiv.

${ }^{4} \mathrm{~J}$. B. Pratt, The Religious Consciousness, A psychological study (1920), New York 1937, les chapitres "The milder form of mystic experience" (pp. 337-362) et "The ecstasy" (pp. 394-429).

"Cp. la définition de M. Pratt: la mystique est "the consciousness of a Beyond" (p. 337).

${ }^{6} \mathrm{H}$. Hempel, "Hellenistisch-orientalisches Lehngut in der germanischen Religion ", Germanisch-romanische Monatsschrift 16 , I928, pp. I89 et suiv., S. Agrell, Senantik mysteriereligion och nordisk nunmagi, Stockholm 193 I, pp. 76-86. 
d'après sa volonté $\Downarrow^{1}$, ceci est naturellement la théologie chrétienne que Snorri emploie comme introduction à sa doctrine euhéméristique des ases" ${ }^{2}$ "La lune fatale 》 (urðar-máni), dans la Saga de Eyrbyggja 52, fait son apparition sur le mur et pas dans le ciel (voir p. 232). Au symposion sur le fatalisme, il y a quatre ans, nous avons traité un petit embryon cosmologique dans Helgakviða Hundingsbana $\mathrm{I}: 3$ et suiv ${ }^{3}$. On peut de plus trouver des traces de la mystique des chiffres et dans l'Edda et dans le manuscrit islandais de Hauksbók ${ }^{4}$. Mais sous tous les autres rapports, resteraient valables les opinions de M. de Vries et de Mme Anne Holtsmark, à savoir que le culte des étoiles est inconnu dans la religion préchrétienne nordique, et que l'astrologie n'émerge qu'au XIVe siècle ${ }^{5}$.

Quelles étaient donc les formes de mystique existantes? D'abord se présente la question systématique de ce qui doit être désigné comme des formes. Il y a des rêves et des hallucinations, des cérémonies de culte et des rites de sorcellerie, des identifications d'une personne avec une autre et des phénomènes d'extase. Beaucoup de ces formes se confondent donc, l'une avec l'autre, commes rêves et visions ${ }^{6}$, tandis que plusieurs, le culte ou le rêve par exemple, peuvent avoir des fonctions entièrement différentes, comme des voies qui mènent à une réalité surnaturelle. C'est pourquoi il nous semble opportun de parler des formes suivantes de la mystique préchrétienne: la mystique rétrospective, perspective et prospective. ${ }^{7}$

1 Edda Snorra Sturlusonar, éd. F. Jonsson, Copenhague I93 I, p. 2.

${ }^{2}$ M. W. Baetke a démontré que ceci et autres choses chez Snorri se rapportent à Martin de Bracara, traduit en islandais (Die Götterlehre der Snorra-Edda, Berlin I950, pp. 49-55).

${ }^{3}$ Åke V. Ström, "Scandinavian Belief in Fate", Scripta Instituti Donneriani Aboensis II, Upsal I 967 , pp. 85 et suiv.

"Voir W. Lange, "Zahlen und Zahlenkompositionen in der Edda ", Beiträge zur Geschichte der deutschen Sprache und Literatur, Halle, 77, I955, pp. 306-348, Viggo Brun, Alt er tall, Bergen 1964, pp. 207-209.

${ }^{5}$ J. de Vries, I, p. 359, Anne Holtsmark, l'art. "Horoskop", Kulturhistoriskt lexikon, 6, Malmœ I961, col. 674 et suiv.

${ }^{6}$ "Meldingane om draumar $\mathrm{i}$ dei isl. sagaene minner mykje om hallusinasjonar og illusjonar, og draumar og dagdraumar går i einannan " (H. P. Hansen, l'art. "Draumar», Kulturhistoriskt lexikon, 3, Malmoe i958, col. 300).

7 Comparez les formes de l'activitée parapsychologique: I. rétrocognition, 2. clairvoyance et télépathie, 3. précognition. Voir Gardner Murphy, "Parapsychology ", The Encyclopedia of Psychology, éd. I. Harriman, 1946, H. J. Eysenck, Sense and Nonsense in Psychology, (1957), Bungay, Suffolk 1963, pp. I06-I4I. 
Notes préliminaires: Des rêves et des visions dans la psychologie

L'étude des rêves et de leur cause a été présente en tout temps et en toute religion ${ }^{1}$. Nous avons un texte, dans lequel le dieu Amon se présente en rêve devant le Pharao Aménophis II (I450-I425), et une clé de songe dans le Papyrus Chester-Beatty III, dont le contenu semble remonter jusqu'au Moyen Empire (2000-1785) $)^{2}$ Nous avons des clés dans le 68 e Pariçišta de l'Atharvaveda, environ l'an $1000^{3}$ et celle qui a été découverte dans les archives d'Assourbanipal du VII ${ }^{\circ}$ siècle av. J.-C. et publiée par M. Leo Oppenheim4. Et nous trouvons le traitement des rêves dans l'Ovsıpoxpırıx́́ d'Artemidoros de Daldis ${ }^{5}$, dans le Talmud judaïque (bBerakhot $55 \mathrm{~b}$, bTa'anith 2Ib), chez Tacite (Hist. 4:83 et suiv.) et Plutarc (De Is. et Os. 28), dans Les mille et une nuits (nuits 225-235, 35 I) jusqu' à Pedro Calderón de la Barca (1600-I68I), La vida es sueño ${ }^{6}$.

Une dissertation psychologique des rêves a été commencée dans deux œuvres entre I 860 et 1870 , tous les deux par des professeurs au Collège de France : M. Alfred Mauri (1817-1892), savant en histoire et en archéologie, et le sinologue Marquis d'Hervey de Saint-Denis (1823-1892)7. On

${ }^{1}$ Roger Caillois, "Dialektiken des Traumes 》, Antaios 4, 1963, pp. 482-500, Les songes et leur interprétation (Sources Orientales, 2), Paris 1959 (couvre presque touts les peuples asiatiques), Carl-Martin Edsman, Mystiker $i$ Vällingby, Halmstad I968, pp. 80-89 (avec bibliographie).

${ }^{2}$ Les songes, pp. 22, 33-36.

${ }^{3}$ Les songes, pp. 215-22I.

${ }^{4}$ A. L. Oppenheim, "The Interpretation of Dreams in the Ancient Near East ", Transactions of the American Philosophical Society, New series, 46:3, 1956, pp. 179373 , trad. franç., Le rêve: son interprétation dans le Proche-Orient ancien, Paris 1959, Les songes, pp. 68-76.

${ }^{5}$ Sur cet ouvrage, éd. Rigaltius, Lutetiae (Paris) r603, voir C. A. Meier, "Der Traum im alten. Griechenland ", Traum und Symbol (Neuere Arbeiten zur analytischen Psychologie C. G. Fungs) Zürich et Stuttgart I963, pp. I55, I 57-162, et Claes Blum, Studies in the Dream-Book of Artemidorus, Upsal 1936. La source d'Artemidor est Posidonius (p. 7r) et l'astrologie babylonienne par entremise de Ptolémy (p. 96). Un successeur d'Artemidor est le muslim Ahmed. Voir Achmetis Oneirocriticon, rec. Fr. Drexl, Lipsiæ 1925.

${ }^{6}$ Caillois, p. 495.

${ }^{7}$ L. F. A. Maury, Le sommeil et les rêves, Paris I 86 I, H. de Saint-Denis, Les rêves et les moyens de les diriger, ( 1867 ), réédit Paris I964. - Une ouvre antérieure est G. H. von Schubert, Die Symbolik des Traumes (18I3), 3. Aufl. Leipzig 1840, une un. peu plus récente F. W. Hildebrandt, Der Traum und seine Verwertung fürs Leben, Leipzig $\mathbf{1} 875$. 
pourrait dire que cette période durait jusqu' aux théories de la psychoanalyse ${ }^{1}$.

L'étude de rêves moderne, comme elle est exercée aujourd'hui, commença aux États Unis, environ 1950. En utilisant des métodes électriques modernes de mesurage, on a réussi à chematiser, et à prouver certaines choses du rôle du rêve dans le rythm de la vie humaine. À un sommeil normal pendent 8 heures, tout le monde a cinque périodes de rêves d'environ deux heures en tout. Grâce à la découverte de la soi-disant période REM (rapid eye movement) on peut actuellement enregistrer le commencement et la termination d'une période de rêve. Le mesurage est effectué par des électrodes sur le paupier. Ces mesurages, ainsi que des mesurages pareils sur la tête, ont permis des expériences réussies de l'importance du rêve pour la santé psychique etc. Des périodes de rêves, sciemment dérangées, causent, entre autre, un déséquilibre psychique².

Une question spéciale, de grande importance pour le mystique, déjà indiquée par le Marquis de Saint-Denis, a été abordée par M. Robert Desoille : la possibilité de diriger les rêves et les visions³.

La présence de visions et de auditions dans les matériaux historiques religieux, cause des problèmes, qui ne peuvent être indiqués ici, que brièvement. Après que M. J. E. Dominique Esquirol (I772-I 840 ), eût donné, entre 1830 et $\mathrm{r} 840$, le nom de hallucination à une forme d'expérience, qu'il avait décou-

${ }^{1}$ S. Freud, Die Traumdeutung, Leipzig et Vienne 1900, Le même, Über den Traum, Wiesbaden x9ox, C. G. Jung, Über psychische Energetik und das Wesen der Träume, Zürich 1948, W. Stekel, Die Sprache des Traumes, Vienne 1923.

${ }^{2}$ Sur ceci voir Jan Oswald, Sleeping and Waking, Physiology and Psychology, Amsterdam et New York 1962 (l'œuvre dominante quant à la recherche du sommeil, traitant le rêve aux pp. 120-145), Traum und Symbol, herausgeg. von C. A. Meier, Zürich $1_{96}$ (part de la théorie de C. G. Jung sur le rêve comme une expression de la subconscience collective; des études sur le rêve en Grèce et en Israel; bonne bibliographie), Thomas M. French et Erika Fromm, Dream Interpretation. A new approach, New York 1964 (interprétation de rêves moderne, psychoanalytique, avec une certaine critique de Freud), D. Foulkes, The Psychology of Sleep, New York I966 (l'œuvre d'ensemble psychologique la plus moderne, où le rêve est traité aux pp. 6I-98, 12 I-208), Richard F. Thompson, Foundations of physiological Psychology, New York 1967 (avec des aspects physiologiques aux pp. 465-473). Une vue générale est donné dans Åke V. Ström, "Modern drömforskning", Kugghjulet 43, x969, pp. $7^{-X I}$.

${ }^{3} \mathrm{R}$. Desoille, Théorie et pratique de rêve éveillé dirigé, Genève I96x. 
verte $^{1}$, certaines liens ont existé entre la psychologie de perception et celle de mystique. Pourtant elles ont travaillé longtemps chacune à son côté. La psychologie de perception se dédica, en cette partie, à des dérangements et à des défauts dans la perception ${ }^{2}$, pendent que les psychologues de religion décrivaient les états inspiratifs, sans essayer de les expliquer psychologiquement ${ }^{3}$.

Une certain importance pour la psychologie de religion, avait spécialement la distinction entre des vraies hallucinations et des pseudohallucinations (V. Kandinsky après Fr. W. Hagen) et la découverte d'images eidétiques4.

${ }^{1}$ P. Schröder, "Das Halluzinieren ", Zeitschrift für die gesamte Neurologie und Psychiatrie (ZgNPs), IоI, I926, p. 599.

${ }^{2}$ E. Naville, "Hallucinations visuelles à l'état normal ", Archives de Psychologie, 8, I909, pp. I-8, K. Jaspers, "Zur Analyse der Trugwahmehmungen 》, ZgNPs, 6, I9I I, pp. 460-535, A. Pick, "Zur Lehre von den Störungen des Realitätsurteils bezüglich der Aussenwelt ", Zeitschrift für Pathopsychologie (ZPtps), I, I 91 2, pp. 67-86, Max Scheler, «Ủber Selbsttäuschungen 》, $i b . \mathrm{pp} .87-16_{3}$, où il démontre la différance entre "Irrtum " et "Täuschung " (pp. 9I-96), Ed. Hirt, "Zur Theorie der Trugwahrnehmungen » $i b$. pp. 422-447, Wilh. Specht, "Zur Phänomenologie und Morphologie der pathologischen Wahrnehmungstäuschungen 》, ZPtps 2, I9I4, pp. I-35, I 2I-I43, 48I-569. C. Schneider, "Über Sinnentrug ", ZgNPs I3I, I93I, pp. 7I98I3, I37, I93I, pp. 458-52 I. Les hallucinations ont été traités par N. Vaschide, Les hallucinations télépathiques, Paris I908 (sur l'existence de la télesthésie), P. Schröder, ZgNPS Iо1, 1926, pp. 599-614, P. Quercy, Etudes surl'hallucination, I-2, Paris 1930. Des résumés dans Jean Paulus, Le problème de l'hallucination et l'évolution de la psychologie d'Esquirol à Pierre Fanet (Bibliotèque de la Faculté de Philosophie et Lettres de l'Université de Liège, fasc. XCI), Liège-Paris I941, M. Merleau-Ponty, Phénoménologie de la perception, Paris 1945, pp. 385-397, Siro Spörli, $\ddot{U} b e r$ die Bedingungen der äussern Wahrnehmungstäuschungen, Winterthur 1959, pp. 49-106 (avec une partie sur la différence entre "Irrtum 》 et "Täuschung ", pp. 49-52).

${ }^{3} \mathrm{Cp} . \mathrm{C}$. Schneider: "Die rein religionspsychologische Literatur zu dieser Frage bringt wohl Material, benutzt aber zur Deutung gewöhnlich völlig popularpsychologische Kategorien ", Die Erlebnisechtheit der Apokalypse des f̈ohannes, Leipzig 1930 , p. 22, n. 67 .

${ }^{4} \mathrm{~V}$. Kandinsky, Kritische und klinische Betrachtungen im Gebiete der Sinnestäuschungen, Berlin I 885. Sur la différence réelle entre les vraies hallucinations et les pseudohallucinations voir Specht, ZPtps 2, 1914, pp. 491-505. Là, p. 505: «Dagegen sagen wir, erklärungsbedürftig sei nicht der Wirklichkeitscharakter, sondern der Wahrnehmungscharakter der echten Halluzination ». - E. R. Jænsch, "Über die subjektiven Anschauungsbilder", Bericht ïber den VII. Kongress für Experimentelle Psychologie in Marburg I92I, Jena I922, pp. 3-49, Le même, Die Eidetik, Leipzig I925, T. Husén, Studier rörande de eidetiska fenomenen (Lunds Universitets Arsskrift, NF, I: 4I, 7), Lund I046. Sur les hallucinations $n p .86-0$. 
Quelques œuvres de la psychologie de religion tiraient profit du point de vue actuel de la psychologie ${ }^{1}$.

La psychologie de perception plus récente pouvait, quand même, mieux orienter la psychologie de vision religieuse. En observant certaines tendences chez les psychologues de gestaltisme, le savant belge A. Michotte pouvait démontrer expérimentalment que p. ex. l'effet "lancement", que nous appercevons, "doit être considéré comme une Forme perceptive (Gestalt)", qui « se caractérise par une structure interne determinée »2. La théorie, maintenant confirmée, que M. Michotte a présentée, "permet aussi de construire systématiquement des expériences paradoxales "»3. Avec ceci la chemin était ouverte pour l'étude des différences entre ce que nous observons (le "percept ") et la réalité qui est la cause de cette observation (stimulus distal). Ces résultats ont été poussés plus loin par p. ex. MIM. James Gibson, Gunnar Johansson et Julian E. Hochberg dans une psychologie de perception nouvelle4. Un savant suédois, M. Gunnar Jansson, a formulé quelques résultats de ces recherches : "Different percepts may be obtained from the same distal stimulus, and the constancy phenomena show that the same

${ }^{1}$ Par ex. K. Weidel, "Zur Psychologie der Ekstase ", Zeitschrift für Religionspsychologie, 2, Halle I908, pp. г90-2x 1, G. Hölscher, Die Profeten, Leipzig 1914, J. Lindblom, Die literarische Gattung der prophetischen Literatur (Uppsala Universitets Arsskrift 1924), Upsal I924, Le même, "Die Gesichte der Propheten ", Studia Theologica I, Riga 1935, pp. 7-28, C. Schneider, Die Erlebnisechtheit, I930, A. V. Ström, Der Hirt des Hermas, Allegorie oder Wirklichkeit?, Leipzig I 936, K. Schmeing, "Gefühl und Wille im eidetischen und 'okkulten' Erleben", Bericht ïber den XV.Kongress der deutschen Gesellschaft fiir Psychologie 1936, Jena 1937, pp. I96-200, Lily Weiser-Aall, Volkskunde und Psychologie, Berlin et Leipzig I937, §. V. Ström, "Red Indian Elements in Early Mormonism ", Temenos, 5, I969, pp. I 20-I68, la tranche "Mysticism ", pp. I59-I6I.

2 A. Michotte, La perception de la causalité (Études de Psychologie, vol. 6), Louvain et Paris I946, p. 82. - Cp. A. Michotte- J. Piaget-H. Piéron, La perception. Symposium de l'Association de Psychologie scientifique de langue française, Paris I955, sur "L'influence de l'expérience sur la structuration des données sensorielles dans la perception $》$, pp. $7-8$ I.

3 A. Michotte, p. 2II. Cp. les pensées de l'auteur sur la notion de la "moi-ité ", pp. $205^{-207}$.

${ }^{4}$ J. E. Hochberg, "Effects of the Gestalt Revolution: The Cornell Symposium on Perception ", dans David C. Beardslee et Michael Wertheimer, Readings in Perception (1958), Princeton, New Jersey, 1964, pp. 525-542. Cp. M. Merleau-Ponty, Le visible et l'invisible, Paris-Mayenne 1964 , et William N. Dember, The Psychology of Perception, New York ${ }^{96} 5$. 
percept may be obtained from different proximal stimuli »1. Il a continué soi-même l'exploration «from the proximal stimulus towards the percept $»^{2}$.

Les résultats ont été appliqués sur la religion Indienne par Irving Hallowell ${ }^{3}$. Nous trouvons, dans un livre de textes psychologiques, des exemples qui font penser à ce que nous verrons dans les textes du Nord ancien : "The conjurer has the power to invoke the pawaganak (des animaux mystiques) who happens to be among his guardian spirits. They manifest themselves audibly to the Indians who sit on the ground, outside the tent. These pawaganak talk and sing like human beings " ${ }^{4}$. On a même exercé de la psychologie de mystique expérimental (J. Marechal, A. Mager, C. Albrecht, J. Lhermitte, K. Gins) ${ }^{5}$, et bien des œuvres ont vu le jour, marquant un rapprochement entre la psychologie expérimentale et la psychologie de mystique. ${ }^{6}$ Quand aux visions et auditions, leur genre est determiné ainsi par un psychologue expérimental: «a sensory experience not based on stimulation of a sens organ $"^{7}$. Leur nature peut être celle de l'hallucination, mais — sélon la recherche récente — plus souvent celle de l'illusion ${ }^{8}$.

${ }^{1}$ G. Jansson, Perceived Rotary Motion. A study of principles for the perceptual analysis of changing proximal stimuli (Acta Universitatis Upsaliensis. Abstracts of Uppsala Dissertations in Social Sciences, 2), Upsal I969, p. 4.

${ }^{2}$ Jansson, p. 6 et suiv.

"I. Hallowell, "Cultural factors in structuralization of perception ", BeardsleeWeitheimer, pp. $55^{2-564}$.

${ }^{4}$ Hallowell, p. 553.

${ }^{5}$ Voir W. Pöll, Religionspsychologie. Formen der religiösen Kenntnisnahme, München I 965 , p. 27.

${ }^{6}$ P. ex. G. Walther, Phänomenologie der Mystik, Olten-Freiburg 1955, Herbert Thurston, S. J., Die körperlichen Begleiterscheinungen der Mystik, Luzern 1956, trad. franç. Les phénomènes physiques du mysticisme, Paris 1 961. Carl Albrecht, Das mystische Erkennen, Gnoseologie und philosophische Relevanz der mystischen Relation, Bremen 1958 , E. Arbman, Ecstacy or religious Trance, I-II, Upsal I $963^{-1}$ 968, et W. Pöll (catholique dogmatique), les chapitres "Erscheinungsoffenbarungen ", pp.

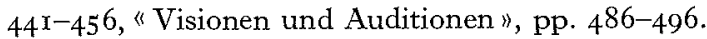

${ }^{7}$ Oswald, Sleeping, p. 76, cf. pp. 76-87, 96-107.

${ }^{8}$ Uwe H. Peters va si loin que de dire: "Optische Halluzinationen kommen ... überhaupt nicht vor ... Bei genauem Nachfragen ergibt sich immer, daß es sich um Illusionen gehandlet hat", Das exogene paranoid-halluzinatorische Syndrom (Bibliotheca Psychiatrica et Neurologica, fasc. 131), Bâle et New York 9967, p. 50. - Là, sur des hallucinations, pp. 45-50, et sur des illusions, p. 5 I. Sur celles-ci plus circonstancié Eliàne Vurpillot, L'organisation perspective. Son rôle dans l'évolution des illusions optico-géométriques (Université de Paris. Faculté des lettres et sciences humaines). Thèse, Paris I 963 . 
Pour comprendre et expliquer les formes suivantes de la mystique, il me semble, davantage, utile de considerer les théories de la parapsychologie, où se trouvent les notions de rétrocognition, de clairvoyance et télépathie et de précognition (voir ci-dessus p. 222). Une confrontation - pas possible de réaliser ici - doit être faite entre la recherche de la mystique et les résultats parapsychologiques ${ }^{1}$.

\section{La mystique rétrospective}

Au mois de mars 1962 on pût lire dans des journaux islandais qu'on avait eu des difficultés de forage à une carrière nouvelle. Les fleurets se brisaient ou les foreuses ne fonctionnaient pas. Le contremaître de la carrière était désarmé devant ces incidents. Une nuit, un des ouvriers rêva qu'un étranger se montra à lui en disant qu'il appartenait au "petit peuple» (huldrufólk), résidant dans les rochers, et demanda un répit pour avoir le temps de trouver une autre demeure pour lui-même et pour sa compagnie - si non les mésaventures continueraient ${ }^{2}$. On fit venir un visionnaire et sur le conseil

${ }^{1}$ Sur l'historie de la parapsychologie voir Rosalind Heywood, "Notes on changing mental climates and research into ESP", Science and ESP, éd. par J. R. Smythies, Londres I967, pp. 47-60, J. B. Rhine, Parapsychology. From Duke to the Foundation for Research on the Nature of Man, Durham, N. Carolina, 1965. - Sur les méthodes et les résultats Charles Richet, Traité de métapsychique, $2^{\mathrm{e}}$ éd. refondue, Paris 1923, J. B. Rhine, Extra-Sensory Perception, Columbia 1934, Le même, The Reach of the Mind (1947), trad. franç. Le nouveau monde de l'esprit, Paris 1955, J. B. Rhine et J. G. Pratt, Parapsychology, frontier science of the mind. A survey of the field, the methods, and the facts of ESP and PK reearch, Springfield 1957, J. Gaither Pratt, Parapsychology. An insider's view of ESP, Londres 1964, Encyclopédie de la divination (Réalités de l'imaginaire, 2), sans lieu d'impression, 1965, le chapitre "Parapsychologie et divination ", pp. 463-50, Sir Cyril Burt, "Psychology and Parapsychology », Science and ESP, pp. 6r-14r. - Quand à la critique scientifique voir entre autre Wilh. Gubisch, Hellseher, Scharlatane, Demagogen?, Munich et Bâle 196I, Reinhold Ruthe, Medien, Magier, Mächte, Über Aberglauben, Okkultismus und Parapsychologie, Wuppertal 1968 , pp. $15-19,39-55$, et C. Albrecht, Das mystische Erkennen, pp. xI-19. - Les rêves, les visions et toutes les formes de la parapsychologie ont été traitées par D. H. Rawcliffe, The Psychology of the Occult, Londres I952.

${ }^{2}$ " Die bösen Geister scheuen das Erz. Metalle sind ihrer Natur nach antidämonisch 》 (G. Schreiber, Der Bergbau in Geschichte, Ethos und Sakralliteratur, Wissenschaftliche Abhandlungen der Arbeitsgemeinschaft für Forschung des Landes Nordrhein-Westfalen, 2I, Köln-Opladen 1962, p. 446). La cause rapportée plus haut montre que Herder et les frères Grimm avont raison - contre Schreiber "daß sich germanische Mythologie in der Volkssage hineingerettet habe " (p. 260). 
de celui-ci les forages furent remis pendant quelque temps. Quand on les reprit, les fleurets et tout l'appareillage fonctionnèrent bien'.

Ceci est une forme de la mystique rétrospective, car le mystique - en ce cas-ci : le rêveur et le visionnaire - trouve une raison cachée pour un cours d'accessibilité générale. Il regarde rétrospectivement et aperçoit le premier anneau d'une chaîne perceptible plus tard. Le rêve, ou même la vision, peuvent aussi être le résultat d'une cause non encore évidente.

Après que M. W. Henzen en I 890 ait attiré l'attention sur les rêves dans le Nord ancien ${ }^{2}$, le savant danois Sofus Larsen désigna en I917 une traduc-

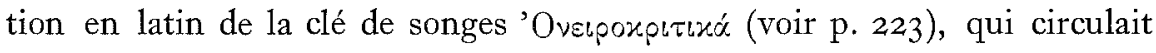
au moyen âge sous le nom de Somniale Danielis ${ }^{3}$. Dans la collection Arnamagnienne à Copenhague, M. Gabriel Turville-Petre en a trouvé une traduction islandaise, encore inédite ${ }^{4}$. Et il souligne avec vigueur ce dont avait $M$. Larsen déjà une idée : la croyance en les rêves est indigène germanique, même si bien des formes et des symboles sont empruntés au Somniale ${ }^{5}$. Notons ici de plus, que les rêves Nordiques ont été étudiés par Mlle Georgia D. Kelchner et M. H. P. Hansen'

Le rêve est bien apte a représenter une forme d'expression de la mystique rétrospective. Sur Viga-Glum nous lisons dans le chapitre 9 de sa saga:

${ }^{1}$ Mekkin S. Perkins, "Superstitions in the Saga Island ", The American-Scandinavian Review 52, I964, p. 415. - Cp. Hermann Jónasson frá pingeyrum, Draumar og dulrúnir ásamt skýringum á eldi og uppruna drauma, Reykjavik i96x, et l'étude scientique: B. Jóhannesson, "Eidetische Untersuchungen in Island ", Zeitschrift fiur Psychologie, 146, I939, pp. т6г-18r. - Sur huldrufólk voir séra Jónas Jónasson, Íslenzkir pjódhættir, 2. éd., Reykjavik x945, pp. 406 et suiv.

${ }^{2}$ W. Henzen, Über die Träume in der altnordischen Sagaliteratur, Leipzig I 890.

"S. Larsen, "Antik og nordisk Drømmetro", Aarbøger for nordisk Oldkyndighed og Historie, III:7, Copenhague 19r7, p. 6r.

${ }^{4}$ G. Turville-Petre, "Dream symbols in Old Icelandic literature ", Festschrift Walter Baetke, Weimar r966, p. 35 r.

${ }^{5}$ Turville-Petre, pp. 346 et suiv. et $35 \mathrm{I}$, Larsen, p. 56: La croyance en rêves est «en fællesgermansk Arv ... den nordiske Drømmesymbolik er ikke original, men - muligvis allerede $\mathrm{i}$ Vikingetiden - har modtaget meget stærk Paavirkning søndenfra. "Cp. Folke Ström, "Tidrandes död ", Arv 8, 1952, pp. 91 et suiv.

${ }^{6}$ G. D. Kelchner, Dreams in the old Norse Literatur and their Affinities in Folklore, Cambridge 1935 (textes et traductions pp. 77-143), H. P. Hansen, Syner og Varsler, Parapsykologiske Fænomener, Copenhague I957 (passim). 
Glúm dreymdi eina nótt: hann póttisk vera úti staddr á bee sinum ok sjá út til fjarōarsins. Hann póttisk sja konu eina ganga útan eptir heradinu, ok stefndi Dangat til pverár; en hon var svá mikil, at axlarnar tóku út fjollin tveggja vegna. En hann póttisk ganga ór garơi a mót henni ok baud henni til sin; ok sídan vaknadi hann.

Qllum pótti undarligt, en hann segir svá: "Draumr er mikill ok merkiligr, en svá mun ek hann rád̆a, at Vigfúss móôurfaðir minn mun nú vera andadr, ok myndi kona sjá hans hamingja vera, er fjollum hæra gekk. Ok var hann um adra menn fram um flesta hluti at virdingu, ok hans hamingja mun leita sér pangat stadfestu, sem ek em».

En um sumarit, er skip kómu út, spurdisk andlat Vigfúss ${ }^{1}$.
Une nuit Glum fit un rêve. Il lui semblait qu'il se trouva dehors dans sa cour regardant vers le fiord. Alors il crut voir une femme arriver de dehors et traverser la contrée et prendre le chemin par Thverâ. Elle était de tellement grande taille, que ses épaules même touchaient les montagnes des deux côtés. Glum eut l'impression qu'il sortait à sa rencontre et l'invitait chez lui. Ensuite il se réveilla.

Tout le monde trouva que ceci était étrange, mais il dit: "Le rêve est grand et extraordinaire, et je l'interprète ainsi - Vigfus, mon grand-père, vient de mourir, et cette femme, plus haute que les montagnes, était son génie tutélaire. On le considérait un homme supérieur aux autres en la plus part des choses, et son génie tutélaire doit maintenant chercher un demeure chez moi."

L'été suivant, quand des bateaux arrivèrent à Islande, on apprit que Vigfus était mort.

Ce rêve annonce un événement qui a déjà eu lieu ${ }^{2}$. Il est dit dans la Saga de Gisli Súrsson:

Gisli var vitr madr ok draumamadr Gisli était un "savant en rêves " et un mikill ok berdreymr. grand « reveur de réalité ».

Gisli a deux "femmes de rêve " (draumkonur, chap. 22), une bonne et une mauvaise. Son beau-frère Vestein occis, Gisli rêve une nuit qu'une vipère

${ }^{1} \mathrm{Si}$ nous ne dirons pas autre chose, les sagas islandaises sont citées selon Islenzk fornit IV-XIII, Reykjavik 1935-1954, et la Edda poëtique selon Neckel-Kuhn, $E d d a, 4^{\mathrm{e}}$ éd., Heidelberg 1962.

${ }^{2}$ Commentaire par Folke Ström, p. 85 , et H. Ljungberg, Die nordische Religion und das Christentum, Gütersloh I940, p. 123. Un rêve pareil, camouflé : un ours dans le rêve de Hoskull est la fylgja de Gunnar de Hlidarendi, mentionnée dans la Njála 23. 
se faufile hors d'une certaine ferme, et la nuit suivant qu'un loup s'échappe de la même maison (chap. I4). Il ajoute :

"en pó vil ek eigi á kveða, hverr vígit hefir unnit; en à hitt horfir um draumana.»
"Moi, je ne veut pas prétendre savoir qui a commis le meurtre, mais les rêves parlent avec une évidence suffisante. ${ }^{1}$

Dans ce rapport, aussi les dieux même peuvent avoir leur place. Dans la Saga de Flóamanna, 2x, Thorgils rêve que le dieu Thor se présente devant lui, sous les traits d'un homme à barbe rousse, qui conduit Thorgils sur des hautes falaises, exige qu'il lui donne un bœuf, ce que l'homme refuse pourtant, étant donné qu'il vient d'être converti au christianisme, et c'est à cet événement que le rêve fait allusion. Comme toujours, la saga a été mise par écrit à l'epoque chrétiene, et une certaine tendance chrétienne est alors habituelle ${ }^{2}$. Ici, au contraire, se présente une tendance païenne : Thorgils fait naufrage à la suite de son refus de sacrifier. Il parvient à regagner la terre ferme en Grœnland de l'est, et persiste, malgré tout, à rester chrétien. À Noël il célèbre la fête chrétienne et demande à ses hommes d'être silencieux et calmes ces soirs-là. Une nuit, cependant, on frappe à la porte après l'heure du coucher et un des hommes se précipite pour ouvrir,

ok vard hann pegar cerr, enn um mor- et en ce moment il tomba en démence guninn deyr hann. et le matin suivant il meurt.

Apparémment il avait vu la face du dieu Thor, et «l'homme ne peut le voir et rester vivant 》 (cp. Exode 33:20)3.

Cette dernière expérience n'était pas un rêve. Plusieures visions de ce genre sont relatées dans la littérature. L'une des plus connues est la vision. et la mort de Thidrandi, qui a été traitée par MM. Grønbech, Strömbäck et

${ }^{1}$ Folke Ström, pp. 89-9 . Cp. Thomas Bredsdorff, «Sanddrømmeren ", Indfaldsvinkler ... tilegnet Oluf Friis, Copenhague 1964, pp. 7-21. L'analyse des rêves de Gisli pp. I5-rg.

${ }^{2}$ Sur cette problème voir Ake V. Ström, "Tradition und Tendenz", Syncretism (Scripta Instituti Donneriani Aboensis III), Upsal I969, pp. 244-262.

${ }^{3} \mathrm{D}$. Strömbäck, Island, bilder frän gammal och ny tid (Skrifter utg. av Samfundet Sverige-Island, I), Lund I93 I, pp. 54 et suiv., Folke Ström, p. 79. 
Folke Ström ${ }^{1}$ Le jeune Thidrandi est trouvé grièvement affaibli et meurt après avoir vu, au temps de la christianisation, neuf génies tutelaires (fylgjur) blanches et neuf noires. M. Turville-Petre donne un commentaire tout à fait correct: ceci n'est pas une vision entièrement païenne et non plus un récit de mission chrétienne. Les femmes "seem rather to be based on pagan beliefs unto which Christian symbols have been grafted $»^{2}$.

Les visions rétrospectives prédominent les événements remarquables à Frodâ, selon la Saga de Eyrbyggja. Une femme des Hébrides, nommée Thorgunna, qui était arrivée en Islande en bateau à voile et qui avait trouvée un domicile à Frodâ, laissa, après sa mort, de la literie et des vêtements précieux, que d'une part elle léga aux gens de la maison, mais dont elle décréta à l'autre part qu'ils devraient être brûlés (chap. $5^{\circ}$ et suiv.). Elle mourut et on l'emmena à Skalholt, mais en cours de route les gens d'une ferme refusèrent de donner à manger aux hommes du convoi funèbre. Alors on entendit un bruit dans une des dépendances et l'on aperçut Thorgunna, tout nue, en train de faire la cuisine (chap. 5I). Quand le fermier de Frodâ voulait brûler les effets comme l'avait décrété Thorgunna, «Thurid, sa femme, glissa ses bras autour de lui et le pria de ne pas brûler la literie ». Elle put ainsi garder la couverture, les draps et le tour de lit.

Bat kveld, er likmenn kómu heim, pá er menn sátu vid mátelda at Fródá, pá sá menn à veggpili eldhússins, at komit var tungl hálft; pat máttu allir menn sjá, peir er i eldhúsinu váru; pat gekk ofugt um hísit ok andsælis. Bat hvarf eigi á brott međan menn sátu vì elda. Fóroddr spurdi Bóri vidlegg, hvat petta myndi boða. Fórir kvað pat vera urðarmána; "mun hér eftir koma manndaudr", segir hann. Eessi tiðendi bar par við viku alla,
Le soir où les hommes du convoi funèbre revinrent, au moment ou l'on était rassemblés autour des feux à Frodâ, les gens virent l'image d'une demi-lune sur la boiserie du mur. Tous ceux qui étaient dans la maison purent la voir. Elle tournait autour de la maison, en sens inverse, et de droite à gauche. Tant que les gens restèrent vers les feux, elle ne disparut pas. Thorodd demanda à Thori Jambe de Bois la signification

${ }^{1}$ V. Grønbech, Religionsskiftet i Norden, Copenhague 1913, pp. 5-10, Strömbäck, Island, pp. 5I-53, Le même, Tidrande och diserna, Lund r949, F. Ström, Arv 8, 1952, pp. 77-1 x9, cp. Gehl, Der germanische Schicksalsglaube, Berlin 1939, pp. I22 et suiv., Baetke, Christliches Lehngut, pp. $\mathrm{x} x$ et suiv., et Turville-Petre, Festschrift Baetke, pp. 345-347.

${ }^{2}$ Turville-Petre, p. 346 . 
at urdarmáni kom inn hvert kveld sem annat.

53. Dat bar hér næst til tiðenda at Fródá, at sauðamadr kom inn með hljódleikum miklum; hann mælti fátt, enn af styggd pat er var; sÿndisk monnum pann veg helat, sem hann myndi leikinn, pvíat hann forr hjá sér, ok talađi vid̀ sjálfan sik, ok fór svá fram um hrid; enn er lidnar váru tvær vikur af vetri, kom saudamadr heim eitt kveld, gekk pá til rekkju sinnar ok lagdisk par nidr; enn um morguninn, er menn kómu til hans, var hann daudr, ok var hann grafinn par at kirkju. de ceci. Thori répondit que c'était une lune fatale - " de ceci s'en suit la mort de beaucoup ", dit-il. La même chose se produisit toute cette semaine là; chaque soir se montra la lune fatale.

Peu après il arriva que le berger entra dans la maison, très silencieux. I1 parlait très peu et ses paroles étaient hostiles. Il parut presque aux gens qu'il était fou, car il se tenait à part, et se parlait à soi-même, et ainsi les choses continuèrent pendant quelque temps. L'hiver déjà bien avancé, le berger rentra un soir, alla à son lit et se coucha. Le matin suivant, quand les gens vinrent à lui, il était mort. Il fut enterré là, à côté de l'église.

(chap. 52 et suiv.)

Après ceci, les gens firent l'expérience d'une véritable suite d'apparitions de fantômes et de visions de revenants (chap. 52-54, cp. Laxd.76). Finalement Snorri gođi eut l'idée d'assigner les revenants de violation de domicile, de brûler le reste de la literie de Thorgunna et de demander à un prêtre de " dire une messe, d'asperger d'eau bénite et de confesser les gens de la ferme » (chap. 55). Alors se prirent fin ces manifestations qui étaient toutes des conséquences de la violation du testament de Thorgunna. - En février r963, séra Kristján Róbertsson en Islande fit savoir qu'il avait souvent été sollicité pour des missions pareilles' ${ }^{1 !}$

Il faut remarquer, que nous avons aussi dans les vieux textes islandais des rêves et des visions littéraires, pas vécus, par ex. le rêve d'Olaf pá dans la Laxd. 3 I, ou celui de Flósi dans la Njála \33, agi par les Dialogues de Gregoire le Grand2.

1 M. Perkins, p. 418.

${ }^{2}$ Folke Ström, Arv 8, pp. "9 et suiv., D. Strömbäck, "Some remarks on learned and novelistic elements in the Icelandic sagas ", Nordica et Anglica. Studies in Honor of Stéfan Einarsson, Mouton 1968, pp. I40 et suiv. 


\section{La mystique perspective}

Cette forme signifie que l'on perçoit quelque chose, que le commun des mortels ne voit pas. Cette mystique se présente sous beaucoup de manières. La vision et l'audition en est une. Dans la Helgakviða Hundingsbana II de l'Edda, on raconte comment d'abord une servante et en suite Sigrun ellemême, voient le défunt Helgi entrer dans le tertre, à cheval, accompagné d'une nombreuse suite. Sigrun peut même faire lit commun avec son mari et l'embrasser (strophes 39-50).

De manière semblable, un berger, dans la Saga de Eyrbyggja, voit comment la montagne de Thorsten Mordeur de Morue s'ouvre et comment les pères morts souhaitent la bienvenue à Thorsten. "À l'intérieur de la montagne il vit de grands feux et entendit un vacarme et des sons de cor éclatants 》(chap. II). Dans la Njála, Skarphedin et Hogni voient comment le tertre de Gunnar de Hlidarendi devient transparent:

Tunglskin var bjart, en stundom dró Il faisait clair de lune, et parfois un fyrir. Deim sýndisk haugrinn opinn, nuage passait. Et voici qu'il leur sembla ok hafð̇i Gunnarr snúizk í hauginum ok que le tombeau était ouvert, et Gunnar sá $i$ móti tunglinu; peir póttusk fjggur s'était tourné dans le tombeau et il ljós sjá brenna i haugimum, ok bar hvergi regardait la lune. Ils crurent voir aussi skugga á. Deir sá, at Gunnarr var kátligr quatre lumières allumées dans le tomok með gleðimóti miklu. Hann kvað vísu beau, et aucune ne projetait d'ombre. ok svá hátt, at pó mátti heyra gorla, Gunnar était gai et la joie était peinte pó at peir væri firr. Siðan lauksk aptr sur son visage. Il se mit à chanter, à haugrinn. voix si haute, qu'ils l'entendaient distinctement, quoiqu'ils fussent loin. Et après, le tombeau se referma ${ }^{1}$.

(chap. 78)

En suite la remarque extraordinaire mystico-psychologique de Skarphedin: "Myndir pú trúa, ef aðrir segði pér?"

"Croirais-tu cela, si d'autres te le disaient? "

L'audition perspective peut s'exprimer dans quelque chose, qui en effet pourrait être décrite comme une illusion dans le sens psychologique: le chant des oiseaux est perçu comme de la langue intelligible, par example:

\footnotetext{
${ }^{1}$ La Saga de Nial, traduite par Rodolphe Dareste (Annales du Musée Guimet. Bibliothèque de vulgarisation [9]), Paris 1896 .
} 
Gudrún hefdi etið af Fáfnis hjarta, ok Gudrun avait mangé du coeur de Fafnir, hun skildi pri fugls rodd. et alors elle comprit la langue des oiseaux.

(Brot af Sigurdarkvidu, la prose à la fin)

De même est dit du roi Olaf le Saint: hann kunni fugls rodd at skilja.

il pouvait comprendre la langue des oiseaux.

(Af Magúsi ok Ólafi Haraldssonum, chap. 7) ${ }^{1}$

L'expérience du culte est une autre forme de la mystique perspective. A l'aide de la bière et de l'hydromel on est devenu à même de comprendre l'existence, et en conséquence $\mathrm{M}$. de Félice peut parler du " role sacré de l'hydromel et de la bière $»^{2}$. D'une manière surnaturelle on a souvent, dans le culte, éprouvé directement que l'offrande était acceptée ou refusée et si le dieu était disposé en faveur du sacrificateur. Une des rares prières, selon Mgr. Helge Ljungberg, qui ait été conservée dans la littérature préchrétienne du Nord ${ }^{3}$, est prononcée par Thorkel à Thverâ:

Freyr, er lengi hefir fulltrui minn verit ok margar gjafar at mér pegit ok vel launat, nú gef ek pér uxa penna til pess, at Glúmr fari eigi ónaudgari af Dverárlandi, en ek fer nú. Ok láttu sjá nokkurar jartegnir, hvártú piggr eða eigi.
"Frey, toi qui as été depuis longtemps mon confident, et qui as reçu des bonnes offrandes de moi et qui les as bien rendues, maintenant je te donne ce bœuf à fin que Glum ne quitte pas Thverâ moins à regret que je ne le fais maintenant. Et maintenant, faismoi voir quelques signes indiquant si tu acceptes mes offrandes ou non. 》

(La Saga de Viga-Glum, chap. 9)

La saga continue: "Au même instant le bœuf beugla fortement et tomba raide mort, et Torkel interpréta ceci comme un bon augure. " La mort du bœuf lui fit comprendre la disposition du cœur de Frey.

Des traits de mystique sont sans doute aussiattachés à l'usage des labyrinthes qui était fréquent dans le Nord comme dans d'autres cultures indoeuro-

${ }^{1}$ Fornamanna sögur, 6, Copenhague I 83 I, p. 445.

${ }^{2}$ de Félice, Essais, pp. 343-347. Cf. Cahen, La libation, Paris I921, et Dumézil, Le festin d'immortalité (Musée Guimet, 34), Paris 1924, pp. II-15, Grønbech, The Culture, 2, les chapitres "Round the ale-bowl", pp. I44-164, et "The creative festival $\gg$, pp. $216-245$.

${ }^{3}$ Ljungberg, p. I24, note $\mathbf{x}$. 
péennes'. Il en existe encore en Angleterre, dans le Nord et en Russie du Nord, et ils sont décrits dans la littérature des pays méditerranéens (Hom. Il. XVIII:59o, Herod. II:I48, Verg. Aen. V:545-6o3, Plin. Nat. hist. XXXVI). M. J. de Vries a notamment démontré que la procession ou la danse dans le labyrinthe représentèrent la voie à la mort et à la résurrection (ainsi peutêtre aussi Beow. 3169 et suiv.), et étaient souvent exécutées à l'inhumation ${ }^{2}$. "Ist es nur eine Laune des Zufalls, daß die Mitte der Labyrinth-Spirale 'Tod' genannt wird? Und daß die Kinder also auch heute noch den Todesweg hüpfen, um sich dann doch wieder herauszuwinden und damit gleichermaßen von Neuem zu Leben zu gelangen? $»^{3}$

Avec cela nous nous approchons à la troisième forme de la mystique perspective: la communauté divine. Nous n'avons pas de textes qui décrivent une unio mystica chez les Septentrionaux. Mais l'on peut pourtant trouver des traces d'une communauté divine qui s'en rapproche beaucoup ${ }^{4}$. De même que le mystique Henri Suso donnait un quart de chaque pomme à la Sainte Vierge ${ }^{5}$, on dit du héros d'une saga (cp. le premier commendement et l'explication de Luther!) :

Hrafnkell elskaði eigi annat goð meir en Hrafnkel aimait Frey plus que tout Frey, ok honum gaf hann alla ina beztu autre dieu et il lui donna la moitié de gripi sina hálfa við sik. tous les objets de valeur qu'il possédait.

(chap. 2) ${ }^{6}$

${ }^{1}$ Voir C. Sterne, Die Troiaburgen Nordeuropas, 1893, H. Güntert, Labyrinth, Heidelberg I932, C. N. Deedes, "The labyrinth", dans S. H. Hooke (éd.), The Labyrinth, London 1935, pp. 3-42, K. Kerényi, Labyrinth-Studien, Labyrinthos als Linienreflex einer mythologischen Idee. 2 erweit. Ausg. (Albae vigiliae, NF, Io), Zürich 1950.

${ }^{2} \mathrm{~J}$. de Vries, Untersuchung über das Hüpfspiel. Kinderspiel-Kulttanz (FF Communications N:o I73), Helsinki I957, pp. 50-83. - De la litérature supplémentaire dans les notes.

${ }^{3}$ de Vries p. 83. Sur les deux chemins des morts voir Ström, dans RinggrenStröm, Les religions, p. 357 .

${ }^{4}$ W. Baetke, "Das Abhängigkeitsgefühl in der germanischen Religion", Vom Geist und Erbe Thules, Göttingen I944, pp. 39-47.

${ }^{5}$ Heinrich Seuse, Leben, éd. Bihlmeyer (Deutsche Schriften), Stuttgart 1907, p. 25. Cp. J. Huizinga, Herfstteij der middeleeuzen, I9 I9, trad. allém. Herbst des Mittelalters, Munich I924, p. 200.

${ }^{6}$ Traduction selon Pierre Halleux, Aspects littéraires de la saga de Hrafnkel (= Bibliothèque de la Faculté de Philosophie et Lettres de l'Université de Liège, fasc. CLXIX), Paris I963, p. 80. - Cp. le commentaire chez Marco Scovazzi, La saga di Hrafnkell e il problema delle saghe islandesi, Brescia 1960, pp. Io-14. 
Dans la Saga de Gísli Súrsson, nous voyons que cette communauté divine peut être de différentes espèces. Gísli vit dans une liaison demi-matrimoniale avec sa bonne femme de rêve (draumkona, chap. 30 ) :

[Konan sú hin betri] býdr honum med Elle l'invite de l'accompagner à sa dosér at fara til sins innis, ok pat pekkisk hann ... Hon bað pau par vera ok una sér vel, " ok skaltu hingat fara, pá er micile, et il l'accepte ... Elle prie que les deux devront y être, "et tu iras ici, pui andask ".

Il fait une poème:

Heim bauð með sér sinum saum-Hlokk grá[ $[u] m$ blakki, pá var brúdr við beiði blid, lofskreyti at rída. quand tu es mort".

La valkyrie des coutures $[=$ la femme] pria l'ornant des louanges [le poète] de monter avec elle son cheval gris à la maison

- la mariée était douce pour moi.

La même saga nous enseigne aussi clairement, que la communauté divine peut subsister au-delà de la mort. D’une situation, assurément inimaginable dans la mystique chrétienne, il est écrit:

Varð ok sá hlutr einn, er nýnæmum pótti gegna, at aldri festi snæ útan ok sunnan á haugi Dorgrims ok ekki fraus; ok gátu menn pess til, at hann myndi Frey svá ávardr fyrir blótin, at hann myndi eigi vilja, at frøri á milli peira.
Il y avait quelque chose de nouveau et de remarquable au sujet du tertre de Thorgrim, car la niège n'y restait jamais, et le sol ne gelait jamais sur le coté sud du tertre. Les gens pensaient que Frey l'aimait tellement à cause du sacrifice, qu'il ne voulait pas qu'il gelât entre eux. (chap. I8)

On raconte quelque chose de semblable au sujet du roi Framarr:

hann blótadi Ârhaug; par festi eigi snjó á. il sacrifiait au 'Tertre de l'année', la neige ne s'y attachait pas.

(La Saga de Ketil hæng, chap. 5)

Cette unio mystica dans le sacrifice atteint son apogée dans $H a ́ v$. I38, où le sacrifice d'Odhinn de lui-même rappelle à celui de Prajäpati et de Kṛ̣na $a^{2}$ :

${ }^{1}$ Fornaldarsögur, 2, Reykjavik I 886, p. I54.

${ }^{2}$ Sur Odhin dans cette strophe voir Mircea Eliade, Le chamanisme, Paris I95 I, pp. 342 et suiv. Il est "le grand chaman » selon Le même, Traité d'histoire des religions, Nouvelle éd., Paris I964, p. 79. - Sur le sacrifice des deux dieux indiens voir Ringgren-Ström, pp. I94 et 204 . 
Veit ek, at ek hekk

vindgameidi á

nætr allar nio,

geiri undadr

ok gefinn Ódni,

själfr sjálfum mér.
Je sais que je pendis

à l'arbre empli de vent

neuf pleines nuits,

par la lance navré

et livré à Odhinn,

moi-même à moi-même remis ${ }^{1}$.

La mystique perspective se révèle en quatrième lieu dans la renaissance. Au début de la Saga de Vatsdøla le brigand mourant, Jœkul, prie que le premier enfant du meurtrier qui a épousé la sœur de Jœkul, soit nommé d'après lui, à fin qu'il renaisse (chap. 2). Cette idée, on la trouve fréquemment. D'une manière surnaturelle on percevait l'identité d'un être précédent, dans un nouvel être ${ }^{2}$. Dans des passages de prose de l'Edda, on en trouve au moins deux exemples: les derniers mots dans la Helgakviða Hjorvarsonar (après strophe 43):

Helgi ok Sváva er sagt at væri endrborin. on dit que Helgi et Svava ont renaquis.

et dans la Helgakvida Hundingsbana II:

Hans dóttir var Sigrún ... hon var la fille de Högni était Sigrun ... elle Sváva endrborin. était la Svava en état rené.

(après strophe 4)

Helgi ok Sigrún er kallat at væri endrborin. Hét hann pá Helgi Haddingjaskadi enn hon Kára Hálfdanar dóttir. on dit que Helgi et Sigrun ont renaquis. Il s'appelait alors Helgi Haddingjaskadi et elle Kara, fille de Halfdan.

(après strophe $5 \mathrm{I}$ )

Evidemment on a eu une certitude surnaturelle que la même personne existait en trois incarnations: Svava, Sigrun et Kara. Une telle croyence de la réincarnation existe aussi dans la mystique moderne suédoise ${ }^{3}$.

${ }^{1}$ Renauld-Krantz, Anthologie de la poésie nordique ancienne. Des origines à la fin du Moyen age (Collection Unesco d'œuvres représentatives, Serie Européenne), Paris I 964, p. 62. Cp. F. Wagner, Les poèmes mythologiques de l'Edda. Traduction française (Bibliothèque de la Faculté de Philosophie et Lettres de l'Université de Liège. Fasc. LXXI). Liège et Paris 1936, pp. I I I et suiv.

${ }^{2}$ Historique et discussion chez Ake V. Ström, Vetekornet, Studier över individ och kollektiv $i$ Nya Testamentet, Upsal 1944, pp. 38-40, 44.

${ }^{3}$ Voir C.-M. Edsman, Mystiker, p. 79 et suiv. 


\section{La mystique prospective}

Dans cette forme quelque chose crée ou prévoit un événement à venir.

Ici aussi, nous mentionnons d'abord le rềve. Des rêves de présage, d'augures néfastes, se trouvent déjà dans l'Edda: Atlamál r4-28, Baldrs draumar I, et ils sont fréquants dans les sagas, par ex. Gisla 24 et 33, Njála 62. Un exemple:

Svá mik nýliga

nornir vekja,

vilsinnis spá

vildi at ek réda:

$\ldots$

Hugða ek hér i túni

teina fallna

pá er ek vildigak

vaxna láta,

rifnir med rótum,

ródnir i blódi,

bornir á bekki

beðit mik at tyggva.
C'est ainsi que les Nornes viennent de me réveiller.

Par des visions de mauvais augure

— il en demanda l'explication.

Il me semble voir, dans l'enclos, de jeunes plantes abattues que j'aurais voulu laisser croître; Elles étaient déracinées, rougies dans le sang.

On les posa sur la table pour me les faire mâcher ${ }^{1}$.

(Guðrunarkviða II:38, 40)

Un rêve prospectif remarquable, avec une vision du dieu, parait dans la Glúma:

Aðr Glümr ridi heiman, dreymdi hann, at margir menn væri komnir par til Fverár at hitta Frey, ok póttisk hann sjá mart manna á eyrunum við ána, en Freyr sat á stóli. Hann póttisk spyrja, hverir par væri komnir. Deir segja: „Detta eru frændr pinir framlidnir, ok bidjum vér nú Frey, at pú sér eigi á brott fordr af pverárlandi, ok tjóar ekki, ok svarar
Avant de prendre son cheval et de partir, Glum rêva que beaucoup d'hommes étaient arrivés à Thverâ pour voir Frey, et il croyait voir une foule de gens sur les sables bordant la rivière, et Frey assis sur une chaise. Il semblait à Glum qu'il demandait qui étaint les gens qui étaient arrivés. "Nous sommes tes pères morts", répondirent-ils, " et nous prions main-

${ }^{1} \mathrm{~F}$. Wagner, Les poèmes héroiques de l'Edda et la Saga de Völsungs. Traduction française, Paris 1929, Jan de Vries, "Das zweite Guðrúnlied ", Zeitschrift fuir deutsche Philologie 77, 1958, pp. I76-199, B. Nerman, "Två unga eddadikter ». Arkeologisk belysning av Drymskviða och Atlamál, Arkiv för nordisk filologi 78, 1963, pp. 126r33. 
Freyr stutt ok reiduliga ok minnisk nú á uxagjof Porkels ens háva». tenant Frey que tu ne sois pas chassé du pays de 'Thverâ, mais ceci ne sert à rien, et Frey repond sèchement et en colère et se souvient de l'offrande que lui fit Thorkel le Grand d'un bœuf ».

(chap. 26)

Il existe donc des visions qui portent malheur. Thord meurt, selon la Njála $4 \mathrm{I}$, peu après avoir vu sa génie tutélaire $(f y l g j a)^{1}$ :

Bat var einu hverju sinni, at peir sátu uiti, Njáll ok Fórdr. Dar var vanr at ganga hafr um túnit, ok skyldi engi hann i braut reka. Fórdr mælti: "Undarliga bregð̆r nú viđ", segir hann. "Hvat sér pú pess, er pér pykkir med undarligu móti vera?", segir Njáll. "Mér pykkir hafrinn liggja hér i dælinni ok er alblódugr allr». Njáll kvaj par eigi vera hafr ok ekki annat. "Hvat er pat pá?", segir Dórdr. " $\bar{u}$ munt vera maðr feigr", segir Njáll, "ok munt pú sét hafa fylgju pína, ok ver pú varr um pik". "Ekki mun mér pat stoða》, segir bórðr, nef mér er pat ætlat》.
Il arriva une fois que $\mathrm{Njal}$ et Thord étaient assis dehors. Il y avait un bouc qui d'habitude allait et venait dans l'enclos, et jamais personne ne le chassait. Thord dit: "Voilà qui est étrange. " "Que vois-tu qui te semble étrange?" dit Njal. - "Il me semble que je vois le bouc couché là dans ce creux, et il est tout sanglant. " Njal dit qu'il n'y avait là ni bouc ni rien d'autre. "Qu'y a-t-il donc?" dit Thord. - "Tu dois être près de ta mort, " dit $\mathrm{Njal}$, "et c'est ton génie que tu as vu; tiens-toi donc sur tes gardes." - "Cela ne me servira de rien ", dit Thord, "si pareille chose doit m'arriver ".

Les rêves et les visions peuvent aussi porter bonheur. Hrafnkel est sauvé par un rêve, du danger d'etre écrasé par une avalanche, qui frappe, à sa place, quelques animaux:

Dá dreymði hann, at maðr kom at honum "Il rêva qu'un homme venait à lui pour ok bað hann upp standa ok fara braut lui demander à se lever et s'en aller le sem skjótast. Hann vaknaji ok fór brutt. plus vite. Il s'éveilla et s'en va. "

En er hann var skamt kominn, pá hljóp «Et quand il s'était éloigné un peu, toute ofan fjallit alt, ok varð undir goltr ok la roche dégringola, et un porc et un griðungr er hann átti. bœuf, appartenants à lui, furent écrasés. "

(Landnámabók, Sturlubók chap. 283, Hauksbók chap. 244)

${ }^{1}$ Cp. Sigurður Haralz, Fylgjur og fyrirboðar, Reykjavik ${ }^{9} 965$. 
Dans la Saga de Hrafnkel, c'est Frey qui se montre dans le rêve, et ses mots peuvent être compris comme des vers. Le texte de la saga est ainsi conçu: Par liggr pú, Hallfređr, ok heldr óvarliga; for pú á brott bú pitt ok vestr yfir Lagarfliót; par er heill pin oll, ce que M. Gutenbrunner fait porter ainsi ${ }^{1}$ :

par liggr pú, Hallfredr, ok heldr ovárliga!

Foer pú bú pitt vestr yfir lagar-Fljót! par er heill pin.
"Tu restes couché là, Hallfred, tu risques gros.

Va t'établir vers l'ouest au delà du Lagarfljot; Ta prospérité y est assurée².

La première femme de l'île de Gotland, Huitastierna, rêve (droymdi henni draumbr) que trois vipères sortirent de son sein - et elle donne le jour aux trois fils (Guta saga, chap. I) ${ }^{3}$. La femme du roi danois Thira attend un rêve concernant la descendance avant la cohabitation conjural (non ante rebus Venereis indulgere constituens, quam matrimonium creandis liberis efficax futurum aliquo per quietem præsagio didicisset, Saxo, Gesta Danorum 9: XI : 2).

Si le rêve ou la vision désignent le malheur, il ne sert à rien de résister. Bjorn hitdcelakappi dit:

Ekki læat ek drauma ráda forum mínum, «Je ne laisse pas le rêve dominer mes actions ",

(éd. Boer, p. 65)

mais il meurt comme l'avait dit le rêve. La vieille mère adoptive aveugle de Thorodd eu raison de prévenir Thorodd de se méfier du tourillon Glasir, qui cause effectivement sa mort. Contre son sort, personne ne peut lutter (La saga d'Eyrbyggja, chap. 63).4

${ }^{1} \mathrm{~S}$. Gutenbrunner, "Eine Traumstrophe in der Hrafnkelssaga? ", Arkiv för nordisk filologi 68, r953, pp. 177 et suiv.

${ }^{2}$ Traduction française selon Halleux, p. 78. - Les bêtes es le mot heill sont commentés par M. Scovazzi, p. Ix.

${ }^{3}$ Guta lag och Guta saga, éd. H. Pipping, Copenhague 1905-07, p. 62. - Cp. Saxo 3 : III : 7 : Postea nocte eidem Proserpina per quietem astare perspecta post triduum se eius complexu usaram denuntiat, et sur les deux passages Hilda R. Ellis, The Road to Hel, Cambridge 1943, p. 72.

"Ström, "Scandinavian belief in fate", Fatalistic beliefs, Upsal 1967, pp. 71 et suiv. 
La forme la plus puissante de la mystique prospective est sans doute la sorcellerie ( $s e j \delta$ ), et dans la forme que M. Strömbäck nomme la sorcellerie divinatoire, où la sorcière, dans un état extatique, s'informe des vicissitudes futures ${ }^{1}$, et dans la forme qui cherche, et généralement arrive à porter malheur à un ennemi². Le sejd doit toujours être exécuté par des femmes, qui parmi les Germains ont eu en tous temps la puissance divinatoire ${ }^{3}$.

M. Vilh. Kiil a voulu identifier l'estrade haute (sejðhjallr), où la sorcière était assise ${ }^{4}$, avec la notion de skjalf que nous avons et dans le mot Hliðskjálf (Grimn. et Skirn., introd. en prose, Hallfr., Lausavisa), et dans des noms locaux en Suède (Vissgärde, Loskälva et ajoutons aussi Vitskövle etc.), qui peuvent avoir été des places d'omination ${ }^{5}$. Il se peut qu'il soit aussi question de sorcellerie au moment de l'inhumation du chef, selon le conte de Ibn Fadlānn. En tout cas, nous trouvons là un exemple splendide de la mystique perspective, quand l'esclave s'écrit en extase qu'elle voit ses parents morts et en suite son maitre défunt dans une existence sublime?.

Non seulement ce rite chamanique pénètre et crée un avenir, mais aussi d'autres formes de mots et rites influents. Oddbjörg prédit le malheur de deux petits garçons, dans la Glúma I2, et déjà sur la pierre de Björketorp, nous trouvons le mot upArAbAsbA >ópurfa-spá, 'prédiction néfaste's. Dans la Njála I2, Svan et ses hommes se trouvent en face d'ennemis puissants.

${ }^{1}$ Strömbäck, Sejd, Lund 1935, pp. 142-150.

${ }^{2}$ Strömbäck, pp. r 50-r 59.

${ }^{a}$ Voir les textes dans W. Baetke, Die Religion der Germanen in Quellenzeugnissen, Francfort sur Main, 1938, pp. 87-91.

${ }^{4}$ Strömbäck, pp. I I0-1 8 . Voir aussi Encyclopédie de la divination, passim.

${ }^{5}$ V. Kiil, "Hliðskjalf og seiðhjallr », Arkiv för nordisk flologi, 75, r96o, pp. 84-I r2. - Voilà les noms locaux p. 93.

${ }^{6}$ "Merkelig nok har man tidligere ikke skjønt at det er en seiðhjallr som trellkvinna blir løfta opp på og der skuer inn i de dødes verden " (Kiil, p. 86).

${ }^{7}$ Achmad ibn Fadlān, Risāla § 90, dans: H. Birkeland, Nordens historie $i$ middelalderen etter arabiske kilder (Skrifter utgitt av Det Norske Videnskaps-Akademi $i$ Oslo, Hist.-Filos. Klasse 1954:2,) Oslo 1954, p. 22.

${ }^{8}$ Lis Jacobsen-Erik Moltke, Danmarks Runeindskrifter, Lommeudgave, Copenhague r942, p. 98 . Voir S. Nordal, Völuspá, gefin út meðskýringum, Reykjavik 1923, p. 57. 
Svanr mælti: "Gakk pú uit með mér; Svan dit: "Viens dehors avec moi. Il lítils mun vid purfa». Sídan gengu peir ne faudra pas grande chose. "Et ils sorut bádir. Svanr tók geitskinn eitt ok tirent tous deux. Svan prit un peau de veifdi um høfud sér ok mælti:

chèvre, l'agita au-dessus de sa tête ${ }^{1}$ et dit:

"Verdi poka

ok verdi skripi

ok undr ollum peim,

er eptir pér sckja ..."

«Vienne le brouillard,

vienne l'effroi

et la terreur sur tous ceux

qui te cherchent. "...

Litlu sídar sé sorti mikill fyrir augu

Les ténèbres devinrent si grandes depeim, svá at peir sá ekki, ok fellu peir pá af baki ok týndu hestunum ok gengu i fen. ofan sjálfir, en sumir i skóginn ...

vant leurs yeux, qu'ils ne voyaient plus rien. Et ils tombaient de leur chevaux, et les perdaient, et s'en allaient dans les marais, d'autres dans le bois ...

Une forme de velatio est liée à des expériences mystiques, aussi bien dans les sagas que dans les chansons folkloriques plus récentes². Dans la Saga de Laxdola, la sibylle morte (volva) se montre à Herdis :

Meyna Herdísi dreymơi, at kona komi at La jeune fille rêva, qu'une femme vint henni; sú var $i$ vefjarskikkju ok faldin hofuddúki. à elle sous les traits d'une tisseuse, la tête envelopée d'un fichu.

(chap. 76)

En qualité de sibylle, elle s'occupe du tissage.

Comme une preuve de la force prospective du sacrifice, on pourrait indiquer le Chant de Darrad, que M. Grønbech a expliqué avec tellement d'élégances. Les Darraðarljód est certainement d'origine plus ancienne que la bataille de Clontarf en ror4, et décrit plutôt la bataille de Confey en $9 x 6^{4}$. M. Ed. Neumann a démontré que la lutte et le tissage sont «in eins gesetzt $»^{5}$, ce qui montre «eine erstaunliche Einfühlungsgabe " Même Tacite, en son ternps,

${ }^{1}$ Remarquez cette velatio mystica, qui se trouve aussi dans Eyrb. 20, Vatsd. $3^{6}$, Reykd. 14 et Yngl. 46.

${ }^{2}$ Kiil, pp. 95 et suiv.

${ }^{3}$ Gronbech, II, pp. 220 et suiv.

${ }^{4}$ F. Genzmer, "Das Walkürenlied 》, Arkiv för nordisk filologi, 7 I, 1955, pp. 168I7I.

${ }^{5}$ Ed. Neumann, Das Schicksal in der Edda, I (Beiträge zur deutschen Philologie, 7), Giessen 1955 , p. I $_{53}$.

${ }^{6}$ J. de Vries, critique de Neumann, Anzeiger für deutsches Altertum 69, 1957, p. 147. 
parle des chants de guerre des Germains, à l'execution desquels (ipso cantu), on peut conclure comment le combat se terminera (Tac. Germ.3). Voici de la mystique pure: l'autel et les murs ayant été rougis par du sang de sacrifice, on a vu, en extas, le champ de bataille rougi, que non seulement on espère mais aussi évoque par le sacrifice ${ }^{1}$. La strophe $3^{\circ}$ de Vellekla de Einar Skálaglam en est une autre preuve:

Flótta gekk til fréttar

felli-Njordr á velli.

Draugr gat dolga Segu

dagrád Hedins váda.

Ok haldbodi Hildar

hrægamma sá ramma.

Týr vildì sá týna

teinlautar fjgr Gauta ${ }^{2}$.
Le faucheur de fuyards (le duc)

alla dans la plaine à l'oracle;

il obtint un jour favorable

à la déesse de discorde (au combat);

celui qui dans la lutte tient, vit de forts griffons de cadavres (des corbeaux).

Ce sacrificateur voulait

anéantir la vie desGots ${ }^{3}$.

\section{Une poème mysterieuse}

Pour finir nous mentionnons une forme de mystique qui contient, dans la vision extatique, des phases du genre en même temps rétrospective, perspective et prospective, une forme qui surtout ressemble à la mystique des grandes religions: celle de l'exaltation prophétique. Un tel visionnaire peut

${ }^{1} \mathrm{~K}$. von See manque de toute compréhension de la vision mystique, quand il demande l'un des deux: la lutte ou le tissage des Valkyries ("Das Walkürenlied", Beiträge aur Geschichte der deutschen Sprache und Literatur, 8r, Tübingen 1959, p. 3). Il estime que le tissage est une image (kenning) littéraire de la lutte (p. I5), car "von webenden Schichsalsfrauen wissen wir nichts". Nous venons d'en trouver un example de la Saga de Laxdela (ci-dessus p. 243). Voir de plus Ladislaus Mittner, Wurd (Bibliotheca Germanica 6), Bern 1955, p. 90: "Die germanischen Schicksalsgöttinnen waren ursprünglich keine Spinnerinnen, sondern Weberinnen. ”

Les mots des Darraðarljó (Ernst A. Kock, Den norsk-isländska skaldediktningen, I, Lund r946, p. r93) :

Niu's vefr ofim enn vollr rodinn
"Maintenant le tissu est tissé et le remblai rougi,

(cp. Rigsp. 37 et $H a ́ r b .40$ ), sont en rapport avec la phrase de sacrifice, rjóda í blódi (de ceci Ström, "Die Hauptriten des wikingerzeitlichen Nordischen Opfers», Festschrift Baetke, Weimar 1966, pp. 331-334).

${ }^{2}$ Kock, p. 69.

${ }^{3}$ Renauld-Krantz, p. 2II. 
" connaître des événements de tous les mondes 》([veita] tíðindi ór allum heimum, Sigrdrifumál avant strophe 5). Il existe des traces de cette vision dans plusieurs chants de l'Edda (entre autre Helreid Brynhildar, Brot af Sigurdar$k v i d u$ ), mais le genre se manifeste le mieux dans la $V q$ luspá.

Plus tôt nous avons analysé ce poème sous un tout autre angle : l'origine de la matière et l'âge des notions ${ }^{1}$. Ici nous traitons la question psychologique de pureté visionnaire.

Le mot $s p a ́$, qui a surtout le sens de 'deviner', provient de la racine indoeuropéenne *spek, qui nous a donné specio en latin, spähen en allemand, et veut dire "voir », "regarder $»^{2}$. Déjà ceci indique que la poème a pour but d'être une manifestation de visions vraies. Y a-t-il une possibilité de décider si cela est le cas?

Conformément à M. William James et Mgr. Tor Andræ, on peut établir trois critères de visions psychologiquement pures : I. apparence spontanée, 2. extrapersonalité, 3. valeur fort subjective ${ }^{3}$.

I. L'apparence spontanée est évidente dans l'usage fréquent des verbes ganga et fara, "aller », et koma, " arriver ». Les images et les personnages arrivent et partent devant les yeux du visionnaire:

Pá gengu regin gll ...

Unz priár kvómu pursa meyjar ...

Uri[á]r kvómu ... æxir at húsi ...
Alors tous les dieux s'en allèrent ...

$$
\text { (strophes 6, 9, 23, 25) }
$$

Jusqu'à ce qu'arrivèrent trois jeunes filles géantes ...

(strophe 8)

Jusqu'à ce qu'arrivèrent trois Ases à la maison ...

(strophe 17 )

${ }^{1}$ Ake V. Ström, "Indogermanisches in der Voluspá ", Numen XIV, 1967, pp. I67-208.

2 "Men moet niet uit het oog verliezen, dat spá ... dus oorspronkelijk 'het zien', 'het schouwen' betekent, wat men evenzeer in het verleden als in de toekomst kan doen" (P. M. Boer-den Hoed, De Völuspá op de grens van twee werelden, Amsterdam I960, p. 7).

3 'Ineffability', 'Noetic quality', 'Transiency', 'Passivity', W. James, The Variety of religious Experience, p. 380, T. Andræ, pp. I76-i 78. Nous avons essayé ces critères aux matériaux chrétiens apocalyptiques (La revelation de $\mathrm{S}$. Jean et Le Pasteur de S. Hermas), dans nos études "Johannes uppenbarelse i ljuset av modern psykologi ", Ny kyrklig tidskrift 2, 1933, pp. I 36-142 et Der Hirt des Hermas. Allegorie oder Wirklichkeit, Upsal ı936, pp. I I-I8. 
Padan koma meyjar ... ór peim see, er ...

Kjóll ferr austan, koma munu Muspellz ... lýjir ...

Surtr ferr sunnan ...

Pá kømr Hlinar harmr annarr fram ${ }^{\mathbf{1}}$

Pá kømr inn mikli megr Sigfodur

Iá kømr inn mæri megr Hlódynjar, gengr Ódins sonr ...2

Sér hun upp koma ... jord ór ægi.

Pá kønr inn riki ...

Par kømr inn dimmi dreki fljugandi.

Pá kemr annarr enn mátkari.
De là arrivent les jeunes filles ...

de ce lac, qui ...

(strophe 20)

Un navire va vers l'est, les troupes de Muspel arrivent ...

(strophe 5 $\mathrm{I}$ )

Surt va vers le sud

(strophe 52)

Alors vient le deuxième chagrin de Hlín (l'apparence d'Odhinn)

(strophe 53)

Alors vient le grand fils du Père-vainceur.

(strophe 55)

Alors vient le glorieux fils de la Terre (= Thor), le fils d'Odhinn va...

(strophe 56)

Elle voit la terre surgir de la mer

(strophe 59)

Alors vient le Puissant $(=\text { Eric })^{3} \quad \ldots$

(strophe 65)

Ici arrive le sinistre dragon en volant

(strophe 66)

Alors vient un autre plus puissant

(Vsp.sk. strophe 44)

2. L'extrapersonalité se trouve entre autre dans l'alternance entre "moi " et " elle " de la sorcière (la Vala) elle-même", et entre 'voir' et 'se faire voir'.

${ }^{1}$ Sur les exemples suivants, voir $\AA$. V. Ström, Numen, p. I96.

2 Dans l'Edda de Snorri la strophe a cette forme: Gengr inn mari / mogr Hlódynjar (Gylfaginning, chap. 5I).

${ }^{3}$ Sur cette déité, voir Ström, Numen, pp. 198-200.

"Sur cette juxtaposition, voir S. Gutenbrunner, "Über $e k$ und hon in der VQluspá", Arkiv för nordisk filologi 72, 1957, pp. 7-12. Là, p. 9: "In ek liegt die Härte des Wissens und die Kraft der Persönlichkeit - hier steht die Seherin auf dem Felde, das sie beherrscht, in hon aber liegt das Bestimmtsein von der Sache her und das Verhältnis der Zugehörigkeit zu Odin. " 
Nous trouvons le verbe sjá, "voir 》, dans les strophes $27,29-3 \mathrm{r}, 35,38$ et suiv., $44,49,59$, et 64 mais synask, "se faire voir ", ou seulement une nouvelle image dans $4-9,17$ et suiv., $24,32,37,40-43,4^{6}$ et suiv., 50-58, 60-63, 65 et suiv. Des perceptions auditives nous rencontrent dans les strophes $42-44$, 46,49 et 58 .

3. La valeur subjective s'exprime, il nous paraît, le plus souvent en ineffabilité, en importance du sujet et en effroi ${ }^{1}$. De la première catégorie on ne trouve rien, d'autant que nous sachions, dans la Vqluspá. L'importance de cette chose ressort de la première strophe, qui contient une formule de l'ancienne littérature indo-européenne de visions, provenue d'états inspiratifs $^{2}$. De même que nous trouvons, dans le Bahman yašt, un dialogue entre Ahura Mazda et Zarathuštra, ou ce dernier décrit ses visions ${ }^{3}$, Mme Boerden Hoed a soutenu que le refrain Vitud ér enn eða hoat? (strophes $\mathrm{r} 7$ et suiv., 33, 35, 39, 4r, 48, 62 et suiv.) est prononcé par Odhinn, et doit être traduit: "Sais-tu encore plus ou quoi? " ${ }^{4}$ Cette interprétation nous semble gagner en vigueur par comparaison avec le refrain dans la petite Vqluspá (Hyndluljód): Viltu enn lengra?, "Veut-tu encore plus loins?" (strophes I7 et suiv. 34, 36, 39, cp. strophe 3r): Viltu enn fleira?, "Veut-tu plus encore? »

L'augmentation de la connaissance est évidente par l'emploi spécifique du verbe vita, «savoir»:

Ask veit ek standa.

Je sais un frêne se dressant.

(strophe 19)

Veit hun Heimdalar hljód um fólgit.

Elle a connaissance du cor caché d'Heimdal.

(strophe 27)

Alt veit ek, Ódinn, hvar pú auga falt. Je sais parfaitement, Odhinn, où tu a caché ton œil.

1 Ström, Der Hirt des Hermas, pp. x6-x8.

(strophe 28)

${ }^{2}$ Voir G. Widengren, Die Religionen Irans (Die Religionen der Menschheit 14), r965, pp. 67-73, et Ström, Numen, pp. I73 et suiv.

${ }^{3}$ Widengren, p. 68.

4 "Legt men nu de woorden 'vitoð ér enn eða hvat?' in de mond van Odin, dan krijgt het referein veel meer zin. Men moet zich voorstellen, dat de völva, Odins medium, na het openbaren van een visioen tekenen van uitputting kan vertonen. Maar zij moet verder gaan met haar onthullingen en Odin wekt haar tot nieuwe activiteit met zijn herhaalde vraag: weet gij nog meer en wat?» (P. M. Boer-den Hoed, pp. 7 et suiv.). 
Fjold, veit hun froeda.

Elle sait beaucoup de sagesse

(strophe 44).

En outre il y a le verbe minnask, "se souvenir ", dans les strophes I et suiv. et $2 \mathrm{I}$.

De la valeur subjective du sentiment, qui s'exprime dans l'effroi, surtout M. Gronbech et Mme Boer-den Hoed, ont donné une image claire. Après un résumé agitant des visions, ce premier dit du visionnaire: "Horror-struck he looks on the upheaval of the times in which honour, the fountain head of all virtue, is submerged and noble men are caught up in the tempest of fate and whirled on by its blinding fury ${ }^{1}$. Et la dernière transmet des impressions semblables: «En anxiété nous voyons dans les images qui se suivent rapidement comment ont lieu les malheurs ... Les visions deviennent de plus en plus sinistres. $\|^{2}$ En conséquence on peut mettre la $V$ qluspá "sous le règne de la mystique $»^{3}$. Et les visions du poème sont une expression de toutes les trois formes, que nous avons proposé: la forme rétrospective, la perspective et la prospective. Le visionnaire de la Vqluspá «takes his place among the religious seers of the world $»^{5}$.

Ainsi il y a une mystique germanique préchrétienne.

1 Grønbech, 2, pp. 303 et suiv.

2 "In angstige spanning zien we in elkander snel opvolgende beelden het noodlot zich voltrekken.... Steeds onheilspellender worden de visioenen " (Boer-den Hoed, p. 5).

${ }^{3}$ "in de mysterieuze sfeer" (Boer-den Hoed, p. 5).

" "Its author is a genius who has pondered deeply on the destiny of men and the meaning of history, and his thoughts flare up into a vision of the cosmic tragedy from the beginnings of time to its fulfilment " (Grønbech, p. 300).

${ }^{5}$ Grønbech, p. 315 . 